\title{
Gall thrips Acaciothrips ebneri (Thysanoptera: Phlaeothripidae) from Ethiopia, a promising biological control agent for prickly acacia in Australia
}

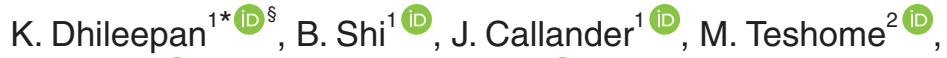 \\ S. Neser ${ }^{3}$ \& K.A.D.W. Senaratne ${ }^{1(1)}$ \\ ${ }^{1}$ Biosecurity Queensland, Department of Agriculture and Fisheries, Ecosciences Precinct, Boggo Road, \\ Dutton Park, Qld 4102, Australia \\ ${ }^{2}$ Central Ethiopia Environment and Forest Research Center, 30708 Addis Ababa, Ethiopia \\ ${ }^{3}$ Forestry E Agricultural Biotechnology Institute, University of Pretoria, Pretoria, 0002 South Africa
}

Based on climatic and plant phenotype matching, native-range surveys were conducted in Ethiopia to identify prospective biological control agents for prickly acacia, a serious weed of grazing areas in northern Australia. Surveys identified a gall thrips, Acaciothrips ebneri (Karny) (Thysanoptera: Phlaeothripidae), as a prospective biological control agent for prickly acacia, based on damage potential, field host range and geographic range in Ethiopia. The gall thrips was imported into a high security quarantine facility at the Ecosciences Precinct, Brisbane, Australia in December 2015 and host-specificity tests are in progress. If approved, the gall thrips would be the first gall insect to be released against prickly acacia in Australia.

Prickly acacia, Vachellia nilotica subsp. indica (Benth.) Kyal. \& Boatwr. (Syn: Acacia nilotica subsp. indica), is a serious weed of grazing areas in western Queensland and has the potential to spread throughout northern Australia (Dhileepan 2009). Prickly acacia infests over 6 million ha of natural grasslands and over $2000 \mathrm{~km}$ of bore drains (a freeflowing Great Artesian Basin bore) in Queensland, and has been estimated to cost primary producers AUD \$9 million annually due to lost pasture production (Dhileepan 2009). Prickly acacia forms impenetrable thorny thickets, restricts stock access to watercourses, competes with native pasture species, and poses a threat to nearly 25 rare and threatened animal species and two endangered plant communities (Spies \& March 2004). Biological control is the most economically viable management option for prickly acacia (Dhileepan 2009).

Biological control efforts commenced in the early 1980s, with native-range surveys conducted in Pakistan, Kenya, South Africa and India (Dhileepan 2009; Dhileepan et al. 2014). These surveys resulted in the introduction of five agents, but only two of them, a seed-feeding bruchid Bruchidius sahlbergi Schilsky (Coleoptera: Chrysomelidae) from Pakistan and a leaf-feeding looper Chiasmia assimilis (Warren) (Lepidoptera: Geometridae) from Kenya and South Africa have become established (Palmer et al. 2012). The impact of $B$. sahlbergi on prickly acacia has been insignificant (Radford et al. 2001), while C. assimilis has established only at coastal sites, and not in the inland regions, where major prickly acacia infestations occur (Palmer et al. 2007). The need for effective biological control for prickly acacia remains a high priority.

Historically, the establishment of biological control agents, introduced into Australia for the control of prickly acacia, has been poor (Senaratne et al. 2006). These agents, although shown to be specific to prickly acacia for release, may not have been adapted to survive the harsh climatic and environmental conditions of western Queensland. Hence, the climate modelling software CLIMEX was used to prioritise climatically suitable areas in the native-range for exploration and sourcing of biological control agents. However, instead of the widely used 'climate matching' approach, a climatic response model was developed based on an Ecoclimatic Index, for a hypothetical insect that would be naturally distributed in the Mitchell Grass Downs in the northwest Queensland (Senaratne et al. 2006). Prickly acacia is a serious problem in this region and only one of the six biological control agents released have become established there. This model was then used to identify climatically suitable areas for exploration and sourcing of agents in the nativerange. Areas in eastern Africa were identified as most climatically similar to the hot and arid 
regions of western Queensland and thus prioritised for sourcing new biological control agents (Senaratne et al. 2006). A literature search (Dwivedi 1993) and herbarium records (National Herbarium, Addis Ababa, Ethiopia) suggested that $V$. nilotica occurs in Ethiopia and hence, search efforts for new biological control agents were redirected to Ethiopia. In this study, based on field host range, damage potential and geographic range, we report a gall thrips Acaciothrips ebneri (Karny) (Thysanoptera: Phlaeothripidae) from Ethiopia as a prospective biological control agent for prickly acacia in Australia.

Potential survey sites in Ethiopia were identified based on herbarium records and the CLIMEX model. Surveys were conducted at 22 sites in July 2014, at 41 sites in December 2015, at 26 sites in November 2016, and at 14 sites in November 2017, in the Adama, Arba Minch, Awash, Dire Dawa, Harar, Melka Werer, Mille, Woldia, Mekele and Shewa Robit areas (Fig. 1). At each survey site, incidence of insects or insect damage were recorded, along with details on the $V$. nilotica subspecies status, plant stage (seedlings, juveniles or trees) and co-occurring vegetation (e.g. other Vachellia species). Field host range of various arthropods collected on prickly acacia was ascertained by investigating co-occurring Vachellia species (specifically looking for insects and mites found on V. nilotica trees; Dhileepan et al. 2013) at the survey sites. Priority was given to galling agents in view of their expected host-specificity (Raman 1984).

Surveys identified natural populations of three prickly acacia ( $V$. nilotica (L.) P.J.H.Hurter \& Mabb) subspecies (subsp. tomentosa (Benth.) Kyal. \& Boatwr., subsp. indica (Benth.) Kyal. \& Boatwr., and subsp. leiocarpa (Brenan) Kyal. \& Boatwr.) in Ethiopia (Fig. 1). Though the possible existence of $V$. nilotica subsp. indica in Ethiopia has been suggested previously (Dwivedi 1993), for the first time, natural populations of V. nilotica subsp. indica have been identified in Ethiopia. The subspecies in the north (i.e. Amhara region) are predominantly $V$. nilotica subsp. tomentosa, the subspecies in the east (i.e. Afar region) are either V. nilotica subsp. tomentosa or V. nilotica subsp. indica; while subspecies in the south (i.e. Oromia) are predominantly $V$. nilotica subsp. leiocarpa. Additionally, the invasive prickly acacia in Australia, V. nilotica subsp. indica, is also very similar to $V$. nilotica subsp. tomentosa (the immature pods and young branchlet tips in subsp. tomentosa are tomentose, while in subsp. indica young branchlet tips are glabrous to sub-glabrous or thinly pubescent). The occurrence of $V$. nilotica subsp. indica, and other morphologically similar subspecies of $V$. nilotica, along with other closely related Vachellia species, make Ethiopia an ideal country to look for species and subspecies specific natural enemies as prospective biological control agents.

For the first time, the thrips A. ebneri which induces rosette galls, was recorded on prickly acacia in Ethiopia. Thrips galls were widespread in the northern and eastern regions of Ethiopia (Fig. 1), on both juvenile plants and mature trees. Thrips-induced galls were found on shoot tips and sprouting axillary buds, with the rudiments of leaves near the feeding sites converted into bunches of rosette-like structures (Fig. 2). In quarantine in Australia and under field conditions in Ethiopia, as a direct result of galling, the entire apical regions of the shoots were completely deformed, often causing shoot-tip dieback. Adult thrips fed on axillary and terminal buds and early signs of gall initiation became evident within a week under quarantine glasshouse conditions $\left(27^{\circ} \mathrm{C}, 60 \% \mathrm{RH}\right.$, and natural photoperiod). In the first week, shoot tips swelled and turned red in colour. The gall continued to grow in size and within three weeks new nymphs were observed in the gall. After four weeks, galls became inundated with new progeny adults, and when mature, turned black (due to necrosis) and began to die back. The gall thrips completed a generation in four to five weeks, as evident from progeny emergence from the gall.

Acaciothrips ebneri was seen on $V$. nilotica subsp. tomentosa at $79 \%$ of sites at which the subspecies was present $(n=23)$ and $V$. nilotica subsp. indica at $96 \%$ of sites at which the subspecies was present $(n=24)$, both subspecies of which have moniliform pods, but not on $V$. nilotica subsp. leiocarpa $(n=8)$ which has pod margins straight or crenate (Fig. 1). Acaciothrips ebneri was not observed on Vachellia etbaica (Schweinf.) Kayl. \& Boatwr. ( $n=9$ sites), or $V$. abyssinica (Hochst. ex. Benth) Kyal. \& Boatwr ( $n=12$ sites), or Vachellia seyal (Delile) P.J.H. Hurter ( $n=4$ sites), which co-occurred at some of the sampling sites. Based on the observed field host range, perceived damage potential and geographic range, A. ebneri was exported to a quarantine facility at the Agricultural Research Council-Plant Protection Research Institute 


\section{EI - Values}

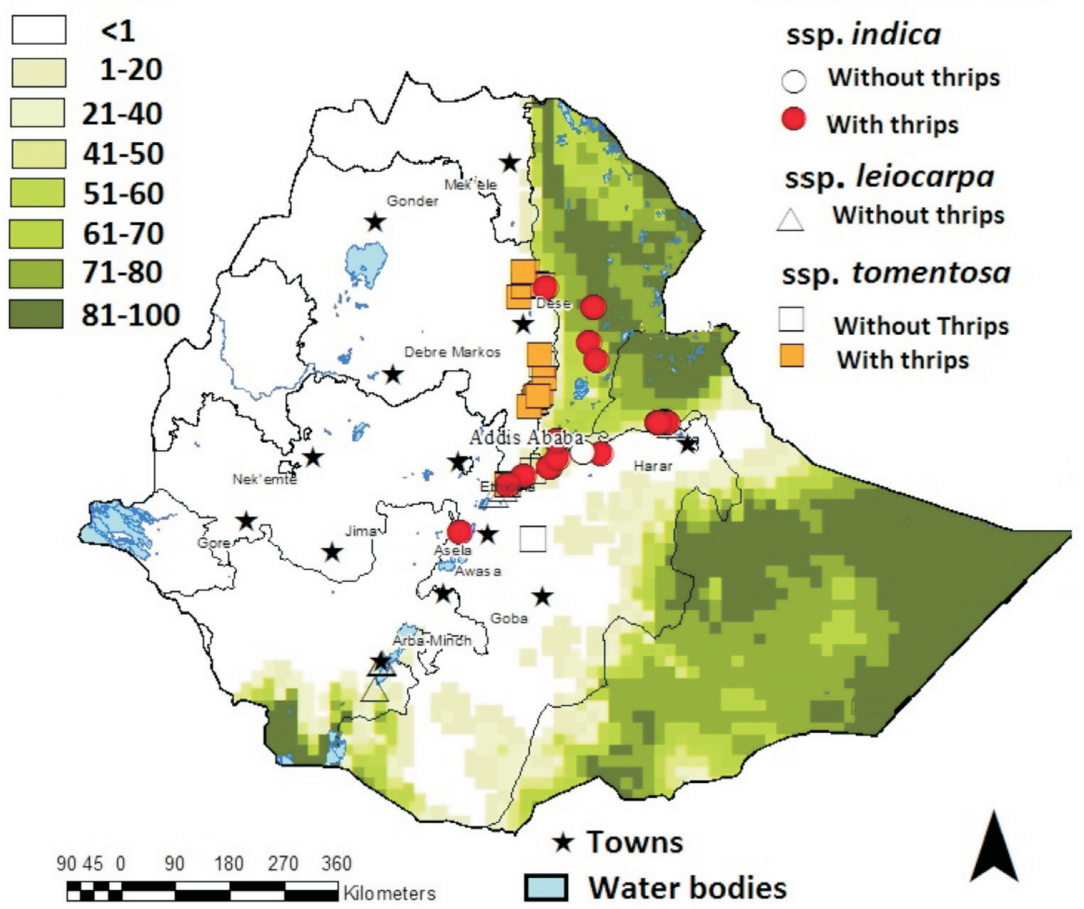

\section{Vachellia nilotica}

ssp. indica

Without thrips ssp. leiocarpa 
(ARC-PPRI), Pretoria, South Africa, for preliminary screening. The susceptibility of the Australian prickly acacia ( $V$. nilotica subsp. indica) to A. ebneri was compared to that of the southern African endemic prickly acacia ( $V$. nilotica subsp. kraussiana). In these preliminary studies (with a minimum of five replications for each subspecies), A. ebneri induced galls only on the Australian prickly acacia ( $V$. nilotica subsp. indica), but not on southern African endemic $V$. nilotica subsp. kraussiana (with fruit pod margins straight or crenate). Though $V$. nilotica subsp. indica is considered to be a native of the Indian subcontinent, no specialist galling insects or mites have ever been reported on the subspecies from India or Pakistan. This is the first time that a specialist galling insect has been reported on the subsp. indica anywhere globally.

Acaciothrips ebneri has been previously reported from Nigeria, Sudan, Egypt and Senegal (ThripsWiki 2016), as part of taxonomic studies. Except for Senegal where it was reported from galls in $V$. nilotica (Bournier 1994), host records for the other countries are not known. It is likely that A. ebneri occurs on V. nilotica subspecies endemic to these countries $-V$. nilotica subsp. indica (Ethiopia), $V$. nilotica subsp. tomentosa (Nigeria, Sudan and Senegal), V. nilotica subsp. nilotica (L.) P.J.H. Hurter \& Mabb (Egypt), and V. nilotica subsp. adstringens (Schumach. \& Thonn.) Kyal. \& Boatwr (Nigeria and Senegal). So far there are no other host records for A. ebneri other than V. nilotica. Field observations in Ethiopia and preliminary host-specificity tests involving two V. nilotica subspecies in South Africa suggest that A. ebneri is host specific, with host range restricted to $V$. nilotica subspecies with moniliform fruit pods (subsp. tomentosa and

\section{REFERENCES}

BOURNIER, A. 1994. Thysanoptera from Senegal: new species and genera. Annales de la Société Entomologique de France 30: 419-429.

DHILEEPAN, K. 2009. Acacia nilotica ssp. indica (L.) Wild. Ex Del. (Mimosaceae). In: Muniappan, R., Reddy, G.V.P. \& Raman, A. (Eds) Biological Control of Tropical Weeds using Arthropods. 17-37. Cambridge University Press, Cambridge, U.K.

DHILEEPAN, K., BALU, A., SENTHILKUMAR, P., MURUGESAN, M. \& SHIVAS, R. 2013. Survey and prioritisation of potential biological control agents for prickly acacia (Acacia nilotica ssp. indica) from southern India. Biocontrol Science and Technology 23: 646-664.

DHILEEPAN, K., TAYLOR, D.B.J., LOCKETT, C.J., BALU, subsp. indica). Based on the field host range in Ethiopia and susceptibility of Australian prickly acacia in quarantine in South Africa, A. ebneri was imported into a high security quarantine facility at the Ecosciences Precinct, Brisbane, Australia, in December 2015 and a colony of A. ebneri has been established. To date over 55 test plant species have been screened and A. ebneri has induced galls and reproduced only on prickly acacia. Galling by A. ebneri on $V$. nilotica subsp. indica in quarantine resulted in shoot tip dieback. Host-specificity tests are still in progress. If approved, A. ebneri would be the first gall insect to be released against prickly acacia in Australia.

\section{ACKNOWLEDGEMENTS}

We thank L. Mound (CSIRO, Canberra, Australia) for identifying the gall thrips, R. Price (ARCPPRI, Pretoria, South Africa) for the quarantine facilities in Pretoria, and the Ethiopian Biodiversity Institute for providing the permit to export the gall thrips. The study was carried out under the Queensland Government's 'War on Western Weeds' initiative. Funding support from the Meat \& Livestock Australia, Rural Industries Research \& Development Corporation and Rural Research \& Development for Profit Programme of the Australian Government (Department of Agriculture and Water Resources) is gratefully acknowledged.

\section{${ }^{\S}$ ORCID iDs}

K. Dhileepan:

B. Shi:

J. Callander:

M. Teshome:

S. Neser:

K.A.D.W. Senaratne: orcid.org/0000-0001-7232-0861

orcid.org/0000-0001-6245-8111

orcid.org/0000-0003-4736-0145

orcid.org/0000-0002-3355-5825

orcid.org/0000-0001-8155-7449

orcid.org/0000-0003-1844-4518

A., SEIER, M., MURUGESAN, S., TANNER, R.A., POLLARD, K.M., KUMARAN, N. \& NESER, S. 2014. Biological control of prickly acacia (Vachellia nilotica subsp. indica): current research and future prospects. In: Impson, F.A.C., Kleinjan, C.A. \& Hoffmann, J.H. (Eds) Proceedings of the XIV International Symposium on Biological Control of Weeds. 21-30. 2-7 March 2014, University of Cape Town, Cape Town, South Africa.

DWIVEDI, A.P. 1993. Babul (Acacia nilotica): A Multipurpose Tree of Dry Areas. Arid Forest Research Institute, Indian Council of Forestry Research and Education, Jodhpur, India.

PALMER, W.A., LOCKET, C.J. \& DHILEEPAN, K. 2012. Acacia nilotica ssp. indica - prickly acacia. In: Julien, M., McFadyen, R.E. \& Cullen, J. (Eds) Biological Con- 
trol of Weeds in Australia: 1960-2010. 18-28. CSIRO Publishing, Melbourne, Australia.

PALMER, W.A., LOCKETT, C.J., SENARATNE, K.A.D.W. \& McLENNAN, A., 2007. The introduction and release of Chiasmia inconspicua and C. assimilis (Lepidoptera: Geometridae) for the biological control of Acacia nilotica in Australia. Biological Control 41: 368-378.

RADFORD, I.J., NICHOLAS, D.M. \& BROWN, J.R., 2001. Assessment of biological control impact of seed predators on the invasive shrub Acacia nilotica (prickly acacia) in Australia. Biological Control 20: 261-268.

RAMAN, A. 1984. Gall insect-host plant relationships an ecological perspective. Proceedings: Animal Sciences 93: 293-300.
SENARATNE, K.A.D.W., PALMER, W.A. \& SUTHERST, R.W. 2006. Use of CLIMEX modelling to identify prospective areas for exploration to find new biological control agents for prickly acacia. Australian Journal of Entomology 45: 298-302.

SPIES, P. \& MARCH, N. 2004. Prickly acacia: National Case Studies Manual. Natural Heritage Trust and Department of Natural Resources and Mines, Queensland, Australia. Online at: http://weeds.ala.org.au/WoNS/ pricklyacacia/docs/Prickly_Acacia_Mgmnt-1.pdf(accessed 11 August 2017).

THRIPSWIKI. 2016. ThripsWiki - providing information on the world's thrips. Online at: http://thrips.info/ wiki/Acaciothrips_ebneri (accessed 2 June 2016). 